\title{
Assessment of human modification of landscapes: Human perceptions vs. analytical indices
}

Stephen C. Trombulak

Department of Biology and Program in Environmental Studies

Middlebury College

Middlebury, VT 05753 USA

trombulak@middlebury.edu

And

William Hegman

Department of Geography

Middlebury College

Middlebury, VT 05753 USA

whegman@middlebury.edu

Running title: Human perception of landscape modification

Key words: analytical index, continental U.S., Human Footprint, human perception, landscape modification, landscape transformation, systematic conservation planning

Corresponding author:

Stephen C. Trombulak

10 Lowell Ln.

Huntington, MA 01050

802-377-7294

trombulak@middlebury.edu

\section{ABSTRACT}

We assessed how close human perceptions of landscape modification matched a multivariate index based on remotely sensed data of the same locations. Using a Human Footprint (HF) map of the continental U.S. (scaled 0-100), we created three series of aerial images, each with ten images distributed evenly across the 10 deciles of HF score. Using a web-based survey, 290 members of the global public ranked the images in one series based on their perception of the degree of human modification. Respondents also reported age, sex, and country. Degree of correspondence between rankings by respondents and by HF score was high, an average of 1.29 units of difference out of a maximum possible of 5.0. Differences among respondents were not explained by age, sex, or general geographic location. These results suggest that human perception of relative landscape modification conforms closely with the relative ranking made by a multivariate, analytical index. 


\section{INTRODUCTION}

An important thread in the evolution of conservation strategies is the understanding that comprehensive goals cannot be achieved solely at a local level uncoordinated with efforts at larger spatial scales. Targets of conservation such as wide-ranging species that live at low densities, migratory species, and important yet stochastic disturbance regimes require conservation planning and implementation at landscape scales.

Conservation planning has increasingly integrated this perspective beginning with the creation of the national park system in the U.S. in 1872 and soon thereafter globally (Trombulak \& Baldwin, 2010). By the second half of the $20^{\text {th }}$ century, planning that involved integration of protected areas into networks surrounded by private lands began. By the 1990's, such planning moved away from dependence on areas selected primarily for idiosyncratic or locally specific features (e.g., scenic views, low cost, recreational opportunity) and toward a more systematic approach to identifying locations that most efficiently contributed to achieving conservation goals across entire regions (Pressey et al., 1993; Margules \& Pressey, 2000; Groves et al., 2002; Margules \& Sakar, 2007).

Inherent to systematic conservation planning is characterization of differential human modification from natural conditions across entire regions. While human modification per se is not necessarily the antithesis of the full suite of conservation goals a network of protected areas might be designed for, intensification of use and modification are (Ellis et al. 2021), and relative extents of modification are an established proxy for the relative magnitude of stresses (e.g., impervious surfaces, roads, human density) that may compromise achieving those goals. Thus, relative quantification of suites of human modifications across large landscapes are needed and must increasingly rely on analytical indices that integrate comprehensive, remotely sensed data. Several such indices have been developed, including the Human Footprint Index (Sanderson et al., 2002; Woolmer et al., 2008), the Naturalness Index (Machado, 2004), and the Human Modification Index (Theobold, 2013, 2016).

While conservation practitioners might readily interpret both the strengths and limitations of any such index, it has been well established that implementation of conservation actions, including new management plans and acquisition of new protected areas, requires engagement and collaboration with the public at large (Villamor, 2014; Bouamrane et al., 2016; Frazão Santos et al., 2018; Mason et al., 2020; Robinson et al., 2020). Many members of the public may, understandably, be less willing to accept implicitly that such indices reflect how they themselves might assess the relative degree of modification based on their own intuitive perception. Thus, public support for landscape-scale conservation plans may potentially be affected by stakeholder confidence that the analytical tools used to develop the plans result in data interpretations that make intuitive sense.

Because of the importance of public engagement in implementing conservation plans, we experimentally addressed the question of whether a person's own perception of landscape modification is concordant with what an analytical index says it is. Similar to research on 
stakeholder assessments of cultural landscapes (Krause, 2001; Larkin \& Beier, 2014; Yang et al., 2021), we engaged a focal group of people to give their perceptions of landscape modification. In our study, participants ranked aerial images of landscapes based on perceived extant of modification, and we then compared their ranking to that done by one analytical index - the Human Footprint Index - of the same locations. The degree of concordance between the two rankings provides insight not only for conservation planners but for members of the public at large who are asked to accept the results of systematic conservation planning algorithms.

\section{METHODS}

\subsection{Calculating the Human Footprint of the continental U.S.}

We calculated the Human Footprint for the continental United States at a 90-m resolution adapting the methods used by Woolmer et al. (2008) for the Northern Appalachian/Acadian ecoregion (NAP) in North America. In brief, the NAP Human Footprint map aggregated four proxy measures of human influence: settlement, access, land use, and electrical power infrastructure. Each 90-m cell was assigned a human influence score (HI) for each of these four proxies. HI scores were summed to create a human influence index (HII) for each cell, which was then normalized (0-100) for a scaled Human Footprint score (HF). For our U.S. Human Footprint map, we excluded data on electrical power infrastructure due to the lack of highresolution data across the entire region.

Human settlement HI scores were determined using 2010 U.S. Census data at the census block level, the smallest spatial scale possible, and population density and dwelling density were calculated for each census block by dividing the number of residents and dwellings by the size of the block. A third raster at 90-m resolution was created from the ESRI Urban Area boundary file urban.sldc. Each of these three rasters was assigned a human influence score from 0 to 10 following Woolmer et al. (2008).

We calculated HI scores for human land use from the 2011 National Land Cover Dataset (NLCD) produced by the U.S. Geological Survey. Each land cover type described in the dataset was assigned a score from 0 to 10 based on the amount of change from "natural conditions" each type represented.

Our scoring system was generally consistent with Woolmer et al. (2008). However, they used the 1992 NLCD, which had a slightly different classification schema than the 2011 dataset. Thus, we adjusted our scores to include the newer category of "Developed, Open Space," which we interpreted as involving less transformation than "Developed Space." Also, unlike the 1992 schema, the 2011 schema combined quarries, strip mines, and gravel pits with desert playa and exposed bedrock under a broader category of "Barren Lands." To avoid assigning a single HI score to all these types, pixels classified in the 1992 NLCD as "Quarries, strip mines, and gravel pits" were used to replace their geographically corresponding pixels in the 2011 dataset as their 
own distinct category, allowing for the assignment of higher modification scores at least to the mines, quarries, and gravel pits that existed in 1992.

Following Woolmer et al. (2008), HI scores for human access were based on proximity to both roads and railroad lines, taking into account the size of the road and whether the railroad lines were active or inactive. We used both 2012 U.S. Bureau of Transportation data on the national rail network and 2014 ESRI cartographic data on roads.

Human influence scores for human settlement, land use change, and access were summed to create a Human Influence Index (HII) score for each cell, which could maximally range from 0 to 36. HII scores were then normalized from 0 to 100 , such that a location's HF score represents a percent of the maximum HII score in the continental U.S. (Figure 1).

\subsection{Assessing human perception of modification}

To see how people would assess human modification of landscapes, we created three separate series of aerial images. Each series was composed of ten images, with each image uniquely representing one of ten equally spaced ranges within the total 0-100 range of the HF scores. To find images that corresponded to different HF scores, we first generated 6000 random points (Create Random Points in ArcGIS Desktop v.10.5) within the Human Footprint map (Figure 1). Each point was then placed into a decile $(0-10,11-20, \ldots, 91-100)$ based on its HF score.

We manually selected three points within each decile (one for each series) so that each point was representative of the larger surrounding area. All points and corresponding areas were evaluated at 1:5000 scale, and an aerial image capturing $1.25 \mathrm{~km}^{2}$ around each selected point was saved (Figure 2).

We created a publicly accessible web site (https://sites.middlebury.edu/trombulak/humanfootprint-welcome-page/) that allowed a person to rank the ten images within a series based on their perception of relative degree of modification. With approval from Middlebury College's Institutional Review Board for human subject research (16 November 2015), we advertised the website widely across our professional societies and personal networks, inviting people to take the survey and to share the link across their own professional societies and personal networks. No attempt was made to be systematic in who the survey was made available to, thus several demographic biases could potentially exist among respondents.

Upon entering the survey, a person selected one of three links that randomly presented them with one of the three series of ten aerial images. They then ranked the ten images based on their perception of the degree to which the area seen in the image had been modified by humans (1-10, least to greatest human modification). No additional information about what was in the image was provided, nor was any guidance given on what might constitute "modification." After ranking all ten images, they submitted their results and were then asked to provide information on their age, sex, country, and if appropriate, postal code. After two 
months, the rate of submission of new surveys declined substantially, and we downloaded the data for analysis. All analyses were done in R (R Core Team, 2020).

\section{RESULTS}

\subsection{Respondents}

Of the 362 people who began the survey, 290 completed the ranking of images in one of the three series. Responses were considered complete if the rankings were completed even if the demographic questions were not. The 290 responses were evenly distributed among the three series $\left(81,105\right.$, and 104 for Series 1,2 , and 3, respectively; $\chi^{2}=3.81$, df $\left.=2, p>.15\right)$.

Of the 290 completed surveys, 157 respondents identified themselves as female, 120 as male, and 7 provided no response. The response rate was greater for females than males $\left(\chi^{2}=4.94\right.$, $\mathrm{df}=1, p=.03)$. Yet females and males did not differ in the series they selected $\left(\chi^{2}=4.26, \mathrm{df}=\right.$ $2, p=.12$ ). Age ranged between 18 and 78 (mean $=41.8, \mathrm{SD}=13.5, \mathrm{n}=283$ ).

Respondents identified themselves as coming from one of twelve countries: United States (238), Canada (17), Slovenia (13), Afghanistan (3), Australia (3), United Kingdom (3), China (2), Bulgaria (1), Ecuador (1), Uganda (1), Ukraine (1), and the United Arab Emirates (1). Six people did not respond to that question. Thus, respondents were overwhelmingly located in the U.S.

Thus, our subsequent comparison of human perception relative to analytical calculation of human modification needs to recognize the potential biases introduced by the sex and geographic location of the respondents, along with potential but unexamined biases in other demographic characteristics, such as education, profession, and prior experience with landscape-scale conservation efforts.

\subsection{Human perception compared to analytic index}

For each image position in a survey (1-10) based on its HF decile, the average difference between the "perception score" and the "index score" differed among the three surveys, so they cannot be combined across surveys. This difference was driven by one of the three surveys (Series C), which was easier for people to score in concordance with the HF index than the other two (Table 1).

A general pattern can be seen in difference scores across the 10 image positions (Table 1). Perhaps unsurprisingly, images that show nearly uniform land cover (e.g., little human modification [HF = 0-10] or extensive modification [HF = 91-100]) tended to be ranked similarly to the HF index than were images with mixed human and natural land cover.

We define a difference unit as a difference of one rank value between the HF rank and the human perception rank. For example, an HF rank of 6 and a human perception rank of 7 equals 
one difference unit. Within a single survey, the theoretical maximum number of difference units across the 10 images in a series is 50 and would occur when the rank order entered by a respondent is exactly opposite to the order made by the Human Footprint score. Thus, the average difference scores across the ten images within a survey range between 0 (perfect match between ranking by human perception and analytical index) and 5 (maximum discordance across all ten images).

The actual range of average differences across all respondents was $0.0-4.6$, with an average of 1.29 among the 290 completed surveys. This average is approximately equal to a total of only 12 difference units out of the possible maximum of 50. Random rankings of ten images, programmed in Excel, results in a significantly higher average number of differences (mean = 3.4 , range $=1.4-5.0, \mathrm{SD}=0.76, \mathrm{n}=100$ random rankings; $t=4.43, p<<.001$ ) than achieved by respondents.

As noted above, average differences varied significantly among the three series $(1.50,1.43$, and 1.00, for Series A, B, and C, respectively, One-way ANOVA, $F=18.26$, df = 2,287, $p<.001$ ), with this difference driven solely by Series $C(t=-5.252, p<.001)$.

Multiple regression analysis does not support that any of the demographic data provided by the respondents explained the inter-individual differences in the correspondence between human perception and analytical calculation $\left(F_{4,271}=1.09, p=.36\right)$. Age was entered as an ordinal variable, and Sex and Location were both entered as categorical variables, Sex with two factors (female and male), and Location with three factors (North America east or west of the $100^{\text {th }}$ meridian [derived from postal codes], and other than North America). Location was factored this way to place respondents into groups that might represent different levels of experience with the types of landscapes shown in each series. Only records that included responses to age, sex, and location were included in this analysis $(n=276)$.

Unsurprisingly, when Series was entered into the model as a three-factor categorical variable $(A, B$, and $C)$, Series $C$ once again emerged as having a significant influence on inter-individual differences $\left(F_{6,269}=8.21, p<<.001\right.$; Series $\left.C t=-5.77, p<<.001\right)$.

\section{DISCUSSION}

These results suggest that human perception of relative landscape modification from natural conditions conforms closely with the relative ranking made by a multivariate, analytical index. While the match between the two is not perfect, with an average of 12 units of difference out of a theoretical maximum of 50 units, it is highly significantly better than random, indicating that the respondents to the survey were interpreting what they saw in the aerial images in a similar way to how the algorithm used to calculate the Human Footprint score integrated data on human settlement, access, and land use.

It is important to note that this study makes no claim that one approach to identifying unmodified landscapes, either human perception or analytical indices, is more correct than 
another. Rather, this study merely counters the potential criticism - a criticism we have heard in our own conservation work in the NAP - that such indices are little more than "black boxes" that are not congruent with how the people who must be involved in the implementation of conservation plans might view the landscape. This does not mean, however, that analytical indices should be replaced by human scoring in the development of landscape-scale conservation plans. That would be impossible for most landscapes if the plans are to be comprehensive with a fine spatial resolution. Rather, it simply provides support for the use of analytical indices in the development of LCPs because it minimizes the chance that such indices could be dismissed as simply being irrelevant to human experience.

Further, this study does not claim that human perception of modification is equivalent to human perception of conservation value. People may value landscapes for conservation for a host of cultural reasons independent of the kinds of modifications known to provide stresses to many aspects of biological diversity. In our survey, respondents were explicitly asked to rank the images based on their perception of modification without reference to any other perceived values for what they observed. While it is important for conservation planners to keep in mind the value of integrating both ecological and cultural values when developing conservation plans (Brown \& Murtha, 2019), the starting point for such integration must include distinct understandings of how each are spatially distributed.

One reason for close correspondence between human perception and analytical index in this study is our choice of the Human Footprint as the index. The Human Footprint index is based primarily on features that are readily observable in an aerial image, such as buildings, roads, and agricultural fields. If a modification index were to be based on features that were not easily observable - such as mercury deposition, invasive species, ecological linkages outside the boundary of the image, or changes over time - correspondence would certainly decline. This argues that in settings where stakeholder engagement is critical to plan implementation, it might be advantageous to base modification indices primarily on features that do not abstract the landscape beyond the point of common experience and perception.

The methods used in administering our survey leave open the possibility that our respondents do not adequately represent the kind of person who would be part of a public stakeholder group. Our results indicate that neither age, sex, nor general geographic location influenced perception of relative modification. Future research might explore whether other demographic characteristics influence how a person views a landscape relative to how that landscape is characterized using remotely sensed data.

\section{ACKNOWLEDGEMENTS}

We thank C. Crosby and I. Evans for initial work developing the U.S. Human Footprint map, and A. Kaminsky for updating the Human Footprint model and work developing the Human Perception survey. Their work was supported by the Middlebury College Funds for Senior Research and Summer Research Assistantships, and by the Department of Biology. We also thank R. Baldwin for improving the manuscript during review. 


\section{AUTHOR CONTRIBUTIONS}

SCT and WH co-designed the experimental methodology and supervised the research. WH was the lead for the GIS analyses. SCT performed the data analysis and was the lead for manuscript writing. WH provided essential input into the final manuscript.

\section{ETHICS STATEMENT}

Approval for human subject research was given by the Middlebury College Institutional Review Board.

\section{DATA ACCESSIBILITY STATEMENT}

Data are archived at Zenodo (10.5281/zenodo.5236691).

\section{CONFLICT OF INTEREST}

The authors declare no conflict of interest.

\section{REFERENCES}

Bouamrane, M., Spierenburg, M., Agrawal, A., Boureima, A., Cormier-Salem, M.-C., Etienne, M., ... Mathevet, R. (2016). Stakeholder engagement and biodiversity conservation challenges in socialecological systems: Some insights from biosphere reserves in Western Africa and France. Ecology and Society, 21(4). https://doi.org/10.5751/ES-08812-210425.

Brown, M., \& Murtha, T. (2019). Integrating natural and cultural resources in North American large-landscape conservation. Environmental Practice, 21(2), 57-68. https://doi.org/ 10.1080/14660466.2019.1601935.

Ellis, E. C., Gauthier, N., Goldewijk, K. K., Bird, R. B., Boivin, N., Diaz, S., ... Watson, J. E. M. (2021). People have shaped most of terrestrial nature for at least 12,000 years. Proceedings of the National Academy of Sciences, 118, e2023483118.

https://doi.org/10.1073/pnas.2023483118

Frazão Santos, C., Agardy, T., Andrade, F., Crowder, L. B., Ehler, C.N., \& Orbach, M. K. (2018). Major challenges in developing marine spatial planning. Marine Policy. https://doi.org/ 10.1016/j.marpol.2018.08.032

Groves, C. R., Jensen, D. B., Valutis, L. L., Redford, K. H., Shaffer, M. L., Scott, J. M., ... Anderson, M. G. (2002). Planning for biodiversity conservation: Putting conservation science into practice. BioScience, 52, 499-512. 
Krause, C. L. (2001). Our visual landscape: Managing the landscape under special consideration of visual aspects. Landscape and Urban Planning, 54, 239-254. https://doi.org/10.1016/S01692046(01)00139-6.

Larkin, A. M., \& Beier, C.M. (2014). Wilderness perceptions versus management reality in the Adirondack Park, USA. Landscape and Urban Planning, 130(1), 1-13. https://doi.org/ 10.1016/j.landurbplan.2014.06.003

Machado, A. (2004). An index of naturalness. Journal for Nature Conservation, 12, 95-110.

Margules, C. R., \& Pressey R. L. (2000). Systematic conservation planning. Nature, 405, 243-253.

Margules, C. R., \& Sarkar, S. (2007). Systematic conservation planning. New York, NY: Cambridge University Press.

Mason, E. T., Kellum, A. N., Chiu, J. A., Waltz, G. T., Murray, S., Wendt, D. E., ... Semmens, B. X. (2020). Long-term participation in collaborative fisheries research improves angler opinions on marine protected areas. PeerJ, 8. https://doi.org/10.7717/peerj.10146.

Pressey, R. L., Humphries, C. J., Margules, C. R., Vane-Wright, R. I., \& Williams, P. H. (1993). Beyond opportunism: Key principles for systematic reserve selection. Trends in Ecology and Systematics, 8, 124-128.

R Core Team (2020). R: A language and environment for statistical computing. R Foundation for Statistical Computing, Vienna, Austria. https://www.R-project.org/

Robinson, N. M., Dexter, N., Brewster, R., Maple, D., MacGregor, C., Rose, K., ... Lindenmayer, D. B. (2020). Be nimble with threat mitigation: lessons learned from the reintroduction of an endangered species. Restoration Ecology, 28, 29-38.

Sanderson, E. W., Jaiteh, M., Levy, M. A., Redford, K. H., Wannebo, A. V., \& Woolmer, G. (2002). The Human Footprint and the last of the wild. BioScience, 52, 891-904.

Theobald D. (2013). A general model to quantify ecological integrity for landscape assessments and US application. Landscape Ecology, 28, 1859-1874.

Theobald D. (2016). Human modification for North America. Data basin. Conservation Biology Institute, Corvallis, Oregon. Available from http://databasin.org/datasets/110a8b7e238444e2ad95b7c17e889b66 (accessed January 2021).

Trombulak, S. C., \& Baldwin, R. F. (2010). Introduction: Creating a context for landscape-scale conservation planning. In S. C. Trombulak and R. F. Baldwin (Eds.), Landscape-scale Conservation Planning (pp. 1-16). Springer. 
Villamor, G. B., Palomo, I., Santiago, C. A. L., Oteros-Rozas, E., \& Hill, J. (2014). Assessing stakeholders' perceptions and values towards social-ecological systems using participatory methods. Ecological Processes, 3(1). https://doi.org/ 10.1186/s13717-014-0022-9.

Woolmer, G., Trombulak, S. C., Ray, J., Doran, P., Anderson, M., Baldwin, R., ... Sanderson, E. (2008). Rescaling the Human Footprint: A tool for conservation planning at an ecoregional scale. Landscape and Urban Planning, 87, 42-53.

Yang, H., Qiu, L., \& Fu, X. (2021). Toward cultural heritage sustainability through participatory planning based on investigation of the value perceptions and preservation attitudes: Qing Mu Chuan, China. Sustainability, 13(3), 1-14. https://doi.org/10.3390/su13031171. 


\section{Figures and Table}

Figure 1. Human Footprint of the continental U.S. with the locations of the 6000 random points generated to develop the survey.

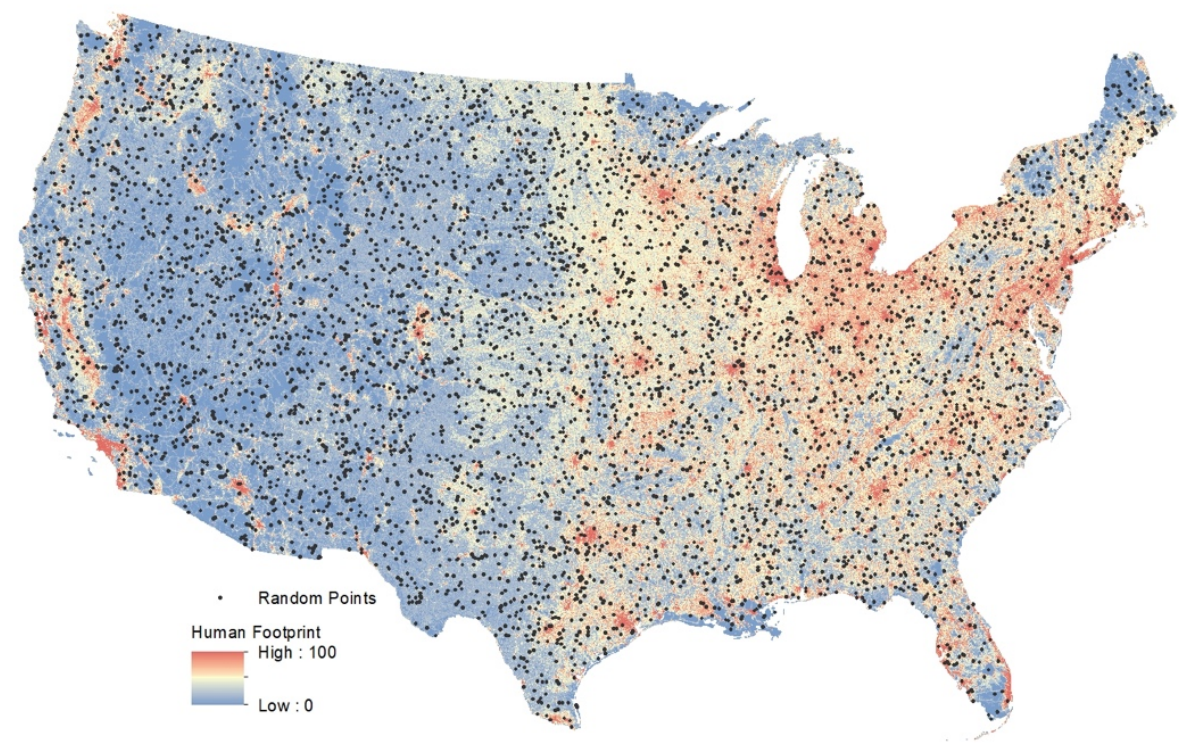


Figure 2. One of the three similar series of 10 aerial images. Image number signifies the HF decile within which the image lies: 1 = HF 0-10, 2 = HF 11-20, ..., 10 = HF 91-100. (Source: Esri, DigitalGlobe, GeoEye, Earthstar Geographics, CNES/Airbus DS, USDA, USGS, AEX, Getmapping, AeroGRID, IGN, IGP, swisstopo, and the GIS User Community.)

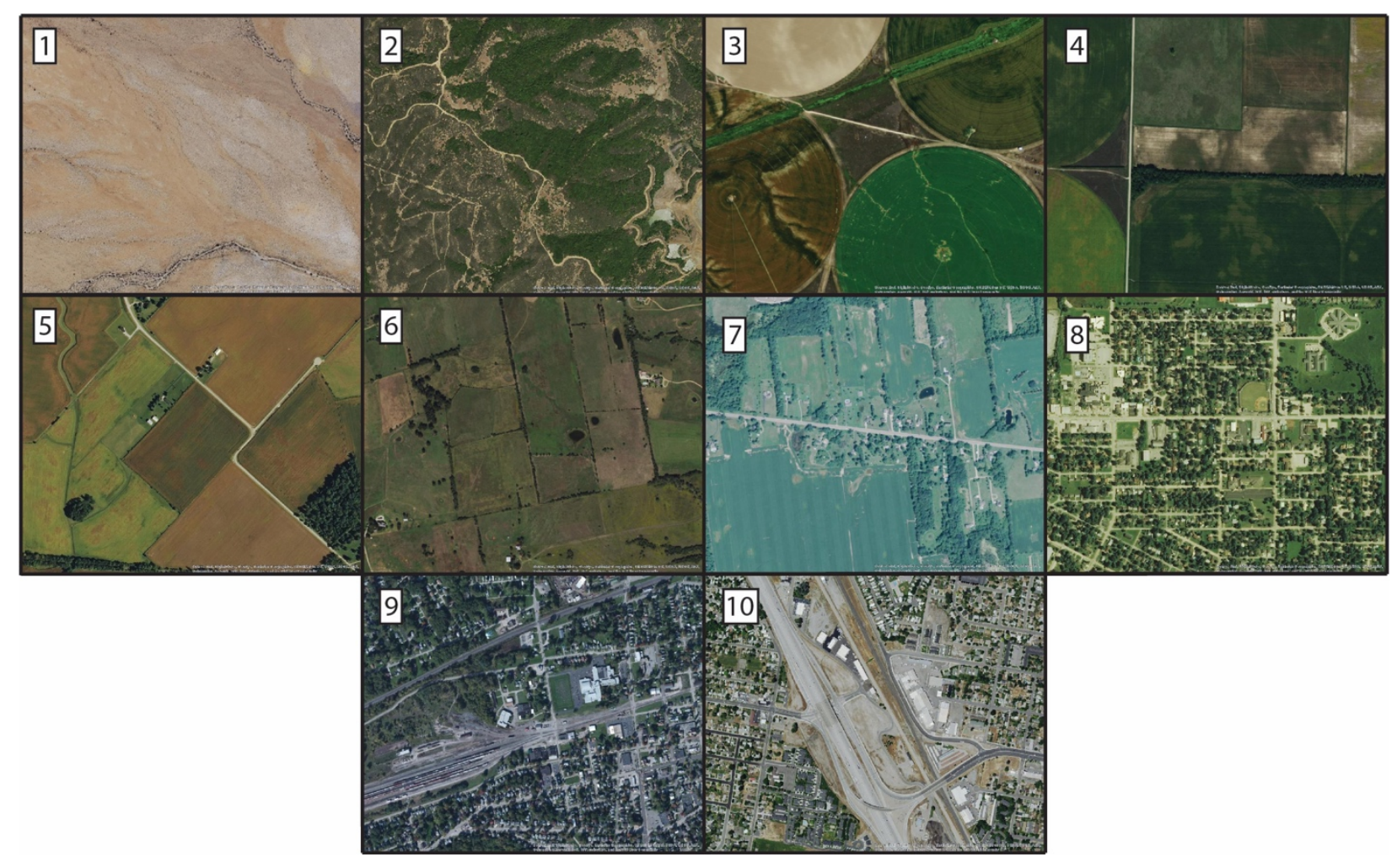


Table 1. Average differences between Human Footprint rank (Image $1=\mathrm{HF}$ score 0-10, $2=\mathrm{HF}$ score 11-20, ..., $10=\mathrm{HF}$ score 91-100) and human perception of relative rank of human modification for each of ten images in three separate series $(A, B, C)$.

\begin{tabular}{|c|c|c|c|}
\hline HF rank & Series A & Series B & Series C \\
\hline 1 & 0.61 & 2.14 & 0.11 \\
\hline 2 & 0.73 & 0.98 & 0.25 \\
\hline 3 & 3.22 & 2.53 & 1.67 \\
\hline 4 & 1.87 & 0.85 & 1.54 \\
\hline 5 & 1.20 & 2.26 & 1.28 \\
\hline 6 & 2.22 & 1.04 & 1.67 \\
\hline 7 & 2.26 & 1.86 & 1.25 \\
\hline 8 & 1.01 & 0.64 & 1.13 \\
\hline 9 & 1.38 & 0.76 & 1.05 \\
\hline 10 & 0.79 & 1.15 & 0.47 \\
\hline Average & 1.50 & 1.43 & 1.00 \\
\hline $\mathrm{N}$ & 81 & 105 & 104 \\
\hline
\end{tabular}

